\title{
Pathology of the Human Aortic Valve Homograft
}

\author{
REGINALD E. B. HUDSON \\ From the Institute of Cardiology and National Heart Hospital, London W.1
}

The gloomy outlook for the patient with severe progressive aortic valve disease has encouraged surgeons to replace the valve by some kind of prosthesis rather than to attempt dilatation or débridement of severely calcified cusps, which often igives unsatisfactory results, and indeed, too commonly proves fatal from the intractable regurgitation which may follow. Improved techniques of bypass surgery of the left heart opened up the possibility of total removal of the cusps and the insertion of some form of man-made valve such as the cagedball types of Starr-Edwards or Magovern, or the tethered plunger type of Barnard, inserted in the proper anatomical site, i.e. below the coronary artery ostia, in contrast to the famous Hufnagel valve which was placed distal to the left subclavian artery. In this way, the hypertrophied left ventricle already chronically starved of adequate blood supply (more often from hæmodynamic causes than from obstructive atheroma of the coronary arteries) becomes better nourished-a crucial factor in such patients.

The caged-ball valve is an engineering masterpiece made to function properly throughout the greatest prolongation of life which even the most optimistic surgeon might anticipate for the patient. It is, however, a hard, rigid, foreign body which the heart will try to dislodge from its sutures; it has a fixed inherent gradient (though the more recent patterns have a larger effective opening), its presence may lead to infection or to intractable anæmia relievable only by removal of the valve; its entry lumen may be obstructed by a thrombotic pannus, fragments of which may embolize; finally, dislodgement of the ball from the cage has been reportedthe ball impacting at the aortic bifurcation-with fatal result. Should internal cardiac massage be necessary after insertion, the hard valve may inflict

Received September 8, 1965.

$\mathbf{U}$ excessive trauma on surrounding tissues. Despite these disadvantages, numerous reports have now accumulated testifying to the gratifying success of these valves in restoring the severely handicapped patient to a near normal life.

Several alternatives to the caged-ball prosthesis have been and are being tried. Dacron cloth cusps proved unsatisfactory in the long term due to thickening or fracture, and attention then became directed to the use of autografts of pericardium or veins (which become thickened by fibrosis in time) or of post-mortem aortic valve homografts. Currently Archer (1965) at Birmingham has been experimenting with preformed mesenteric "valves" made by enclosing a portion of mesentery between two halves of a valve mould inserted inside the abdomen for 6 weeks.

The use of aortic valve homografts stems from the experimental work of Lam et al. (1952), who placed the graft in the descending aorta of dogs. The late results were disappointing owing to shrinkage of the graft, though better graft survival was obtained if the dog's own valve was first made regurgitant, because the graft cusps then underwent more movement. Following this work, several teams reported successful post-subclavian replacement in humans, e.g. Murray (1956), Beall et al. (1961), and Kerwin, Lenkei, and Wilson (1962).

The pioneer surgeon to insert an aortic valve homograft into the correct sub-coronary ostial position in humans was Ross in 1962 at Guy's Hospital in London: it was placed in a man of 43 years with calcific aortic stenosis and atrial septal defect (which was also repaired at operation); the graft was prepared by the method of Duran and Gunning (1962), being first trimmed to reduce it to the valve ring with 3 commissural struts. Ross has now done numerous such replacements both at Guy's Hospital and at the National Heart Hospital, and he included some early cases in his report in 1963; his work has 
encouraged others in this heroic enterprise, e.g. Barratt-Boyes (1964) in New Zealand and Bigelow in Canada. Several other centres are trying the method and doubtless will be reporting in due course.

Although it is probably too soon to give a balanced judgement on the final outcome of such work, many incapacitated patients have been restored to normal life, or have been greatly relieved of their symptoms, some for two years or longer.

The writer has performed over 20 necropsies on patients in whom the homograft inserted by Ross has failed for one reason or another, and the present paper records the findings in a representative selection, illustrating the normal fate of such valves and the more important complications that may follow their insertion. It should be emphasized that in all cases, medical treatment was no longer able to offer adequate relief of symptoms, so that the patients could be considered as bad risks for surgery (as indeed are most patients undergoing aortic valve operations).

\section{NORMAL HOMOGRAFT}

Figure 1 illustrates the appearance of the normal homograft. It comprises a sleeve trimmed just below the valve ring and scalloped along its upper border into anchoring projections above the cusp commissures. The sketch on the right shows the anatomy of the area from which the graft is taken from the donor heart and into which it is inserted in the host. The scalloped upper margin is clear of the coronary ostia, and the straight lower margin includes the upper limits of the interventricular septum, mitral valve, and the bundle of His, which courses in the lowermost posterior part of the membranous septum.

These homografts are taken from donor hearts as soon as possible after death, soaked overnight in 0.2 per cent chlorhexidine, trimmed, graded into sizes, and sterilized by exposure to ethylene oxide vapour for 24 hours. They are then freeze-dried and stored in vacuum in glass tubes, being reconstituted for use by immersion in saline for 20 minutes at $37^{\circ} \mathrm{C}$. The homograft thus represents a dead framework; the cusps are avascular except in the immediate area of attachment, in about 25 per cent of adults aged 20-40 years (Clarke, 1965), but the aorta and septum are not. It would be expected, therefore, on the basis of corneal transplantation, that the major portions of the cusps would survive more or less unchanged and, indeed, this has proved so.

After removal of the recipient's valve cusps via a supravalvar aortic incision, the graft is sutured into place. To do this, the sleeve is turned inside out and its lower rim is sutured by continuous stitch first; it is then "pulled through", and its upper rim sutured similarly, ensuring that the coronary ostia are quite unobstructed. Fig. 2 illustrates an example from a patient who died soon after operation; B shows an overhead view, A shows the valve after cutting open, and $C$ shows a longitudinal section through the area, the graft being on the right and separated from the host's left atrium by a space
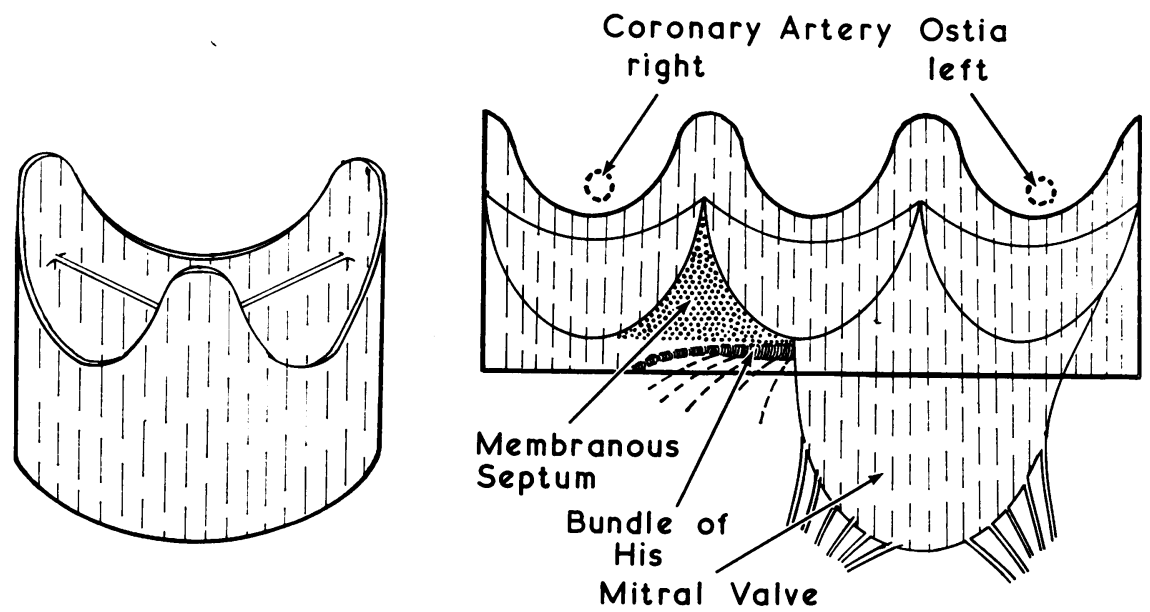

FIG. 1.-Diagram of homograft valve sleeve (on the left), showing the scalloped upper border rising well above the cusp commissures. On the right is shown the area included in the graft, and the site into which it is inserted in the host. Note the scalloping to clear the coronary ostia, and the straight lower border which contains portions of the muscular and membranous interventricular septum (with the bundle of His and its bifurcation) and the base of the mitral valve. 


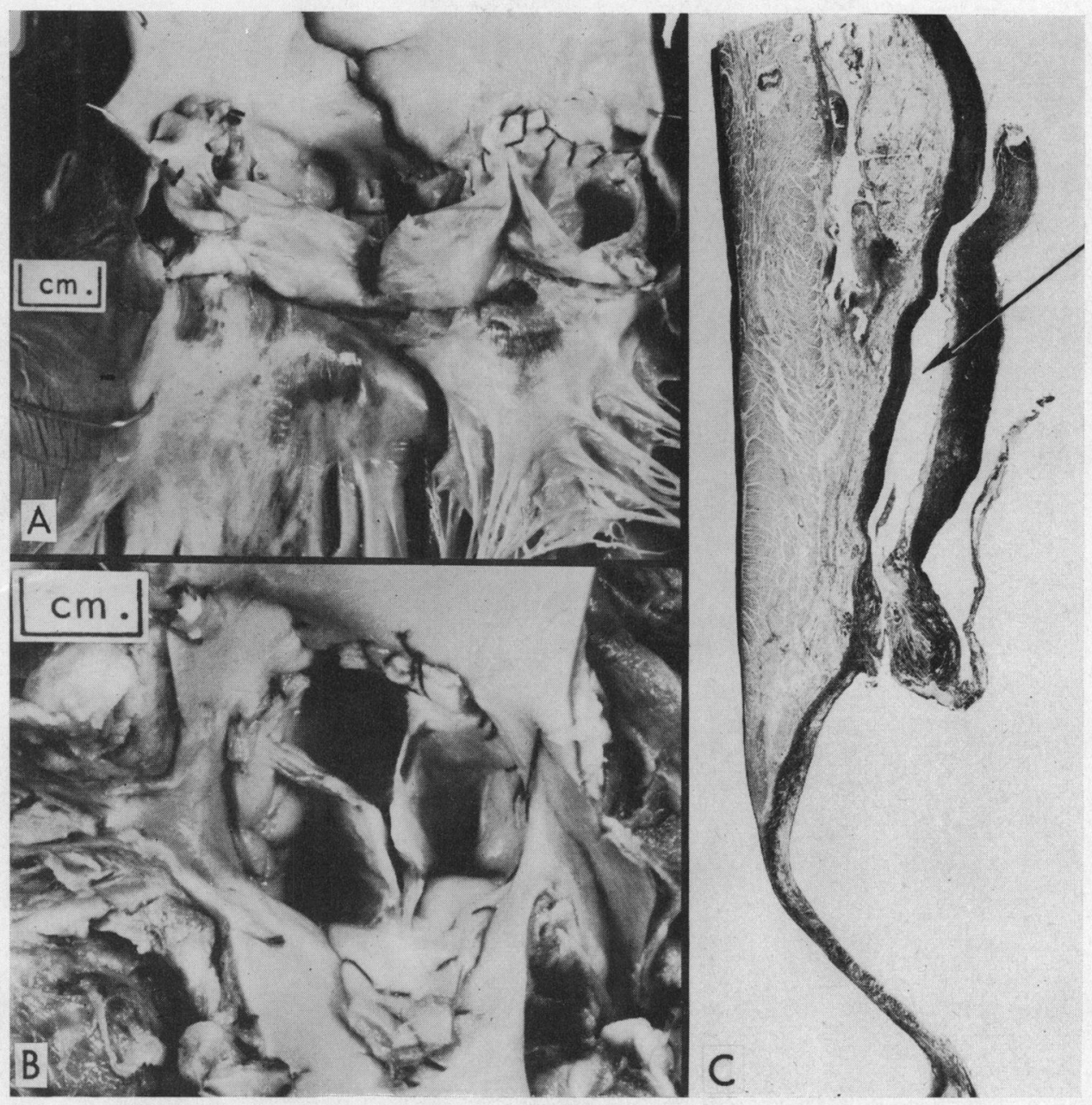

FIG. 2.-Aortic valve homograft a few hours after insertion. (A) shows the graft in the opened heart and (B) shows it from above before opening. Note the normal mitral valve and the 2 coronary arteries (at the sides of the picture). (C) shows a longitudinal section through the graft valve to include the host left atrium and mitral valve; the graft is tethered only by sutures at top and bottom, and there is a trace of thrombus in the lower part of the space (arrow) between the graft aorta and that of the host. The lower limit of the graft is doubled on itself during insertion. (Elastic-van Gieson. $\times 3$.)

containing a trace of thrombus near the lower end.

Figure 3 shows the histology of the dead graft aorta $(\mathrm{A}, \mathrm{C})$ compared with the corresponding host aorta $(B, D)$; the media of the graft is almost devoid of nuclei (A), but elastic stain (C) shows little difference from the normal host aorta (D). (E) shows an area of dead myocardium in the lower end of the graft. The cusps show subendothelial hæmorrhage on the right of $(F)$; or a lesser degree of infiltration by host leucocytes, as in (G).

Graft after 2 Weeks' Insertion (Fig. 4). There are now signs of fibrinous deposition along the scalloped upper border of the graft, so that one or two of the sutures appear filmed over (A). Longitudinal section shows a large hæmatoma between graft and host tissues, which are connected only by sutures (B).

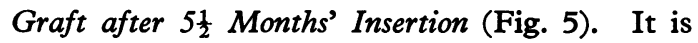
now difficult to realize that the grafted valve in (A) is not the host's own valve; the sutures along its upper border (and in the aortic approach incision) are almost buried in fibrous tissue. Some fibrous thickening can be seen in the bases of the central 2 cusps, continuous with endocardial thickening of 


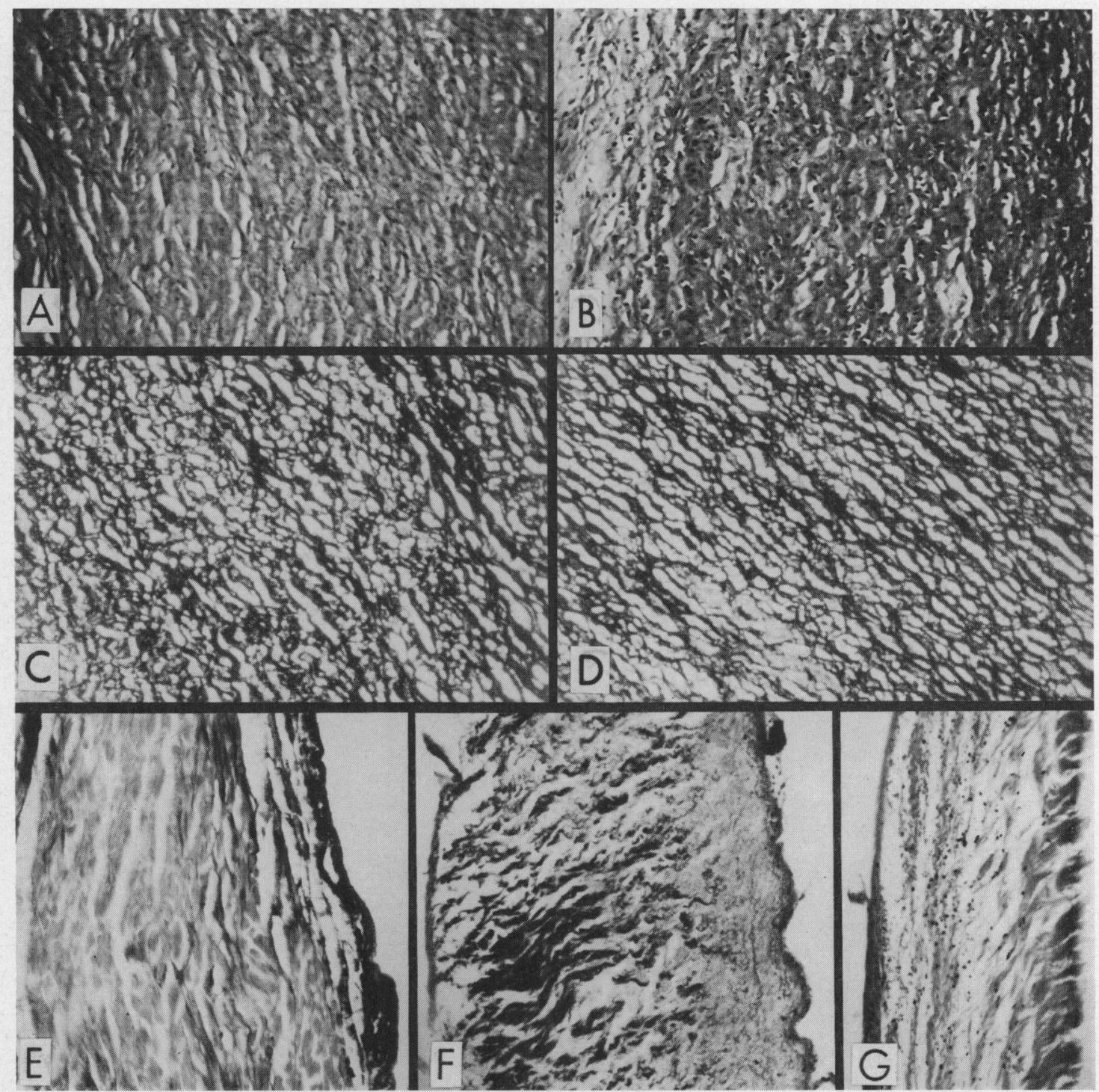

FIG. 3.-Histology of average aortic valve homograft a few hours after insertion. (A) Aortic media showing the shrunken dead nuclei, compared with the normal appearance of the host aorta (B). (C) Aortic media showing almost normal retention of elastic tissue, compared with the host aorta (D). (E) Dead septal myocardium of graft. (F) Valve cusp showing hæmorrhage (on the right). (G) Valve cusp showing round-cell infiltration. (A, B, G: hæmatoxylin and eosin.; C, D, E, F: elastic-van Gieson. All $\times 90$.)

the septum below the graft. The black bristle is inserted into a crevice between graft and host. Longitudinal section shows the basal cusp thickening, and the organizing blood clot between the graft and host (B). (C) shows the shelving off of the upper limit of the graft to the host aortic intima, and (D) shows the same process at the lower end.

Graft Histology after 23 Months (Fig. 6). The graft failed after 23 months and was replaced by a Starr-Edwards prosthesis. Histology shows good preservation of the aortic elastic tissue (A), but thickening of the cusp base is now more extensive (B); the freer portion of the cusp, however, is only moderately thickened (C). Scattered in the graft are small foci of cells which are pyrinophilic (D), presumably representing the only evidence of an immunological response to the foreign tissue. 


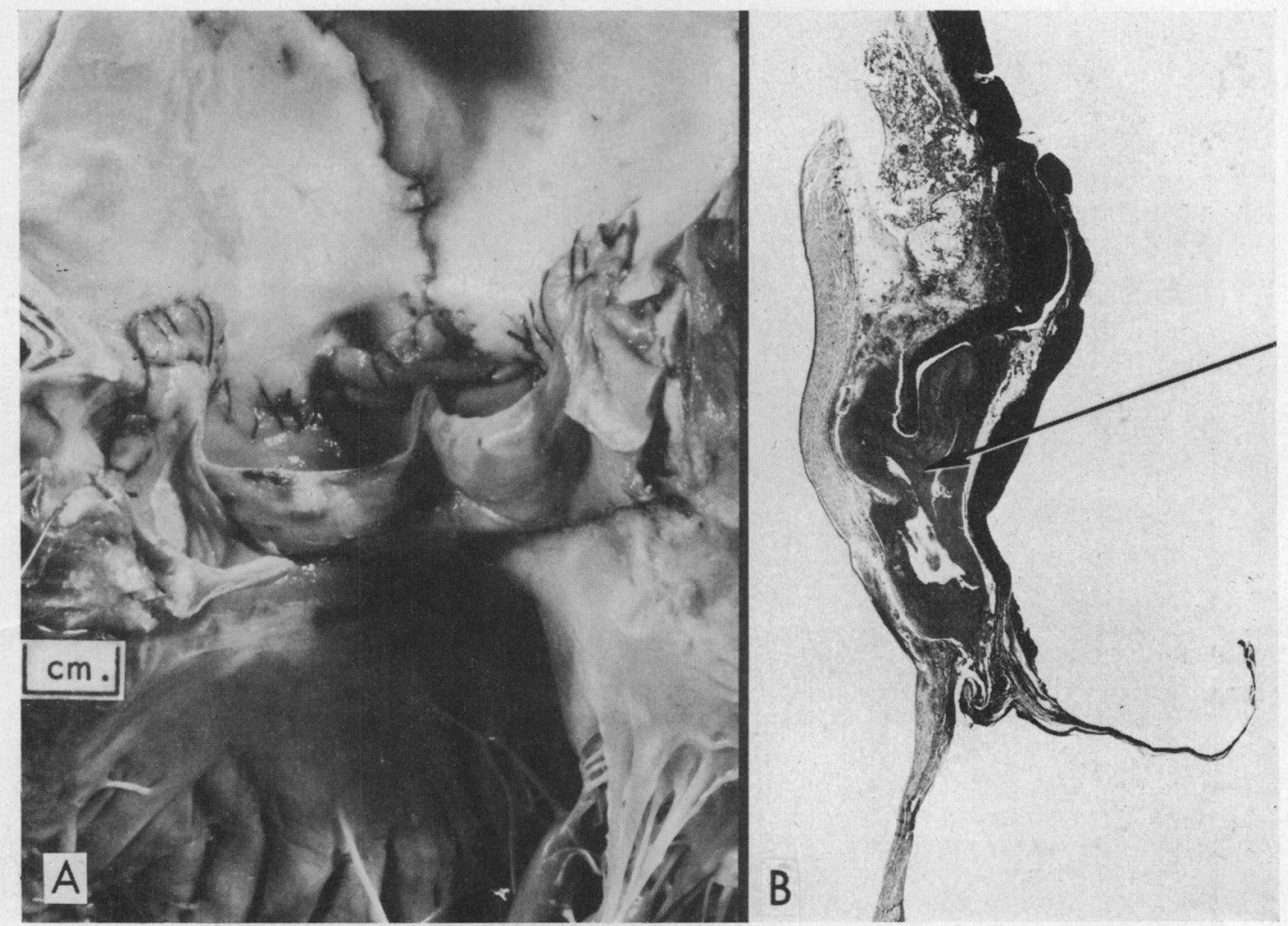

FIG. 4.-Homograft 2 weeks after insertion in a man of 50 years. After the operation, the patient developed heart block necessitating artificial pacing. (A) View of the opened valve; some of the sutures are beginning to be filmed over with fibrin. Note the normal mitral valve. (B) Longitudinal section showing the graft tethered at top and bottom and separated from the host tissues by a large hæmatoma (arrow). (Elasticvan Gieson. × 2.)

\section{Complications of Aortic Valve Homografting}

All patients dying within a few days of operation have shown the post-perfusion pulmonary syndrome of congestion and odema, the cause of which is obscure; experimental work at the Postgraduate School in Hammersmith suggests that it is possibly related to a constituent of the perfusing blood in the bypass apparatus (Nahas et al., 1965), but the writer considers that, in the human, failure of the left ventricle must play an important part. Another hazard, common to all such operations, is cannulation trauma in the proximal portions of the coronary arteries; in one case there was local dissection with thrombosis causing compression occlusion of the lumen with resulting myocardial infarction. The latter may also result from embolism from the operation site (calcified particles, thrombus or adipose tissue) or from accidental ligature of a major coronary artery branch.

Other complications encountered were as follows.
Aortic Hamorrhage from Sepsis in Graft Area (Fig. 7). This led to death in a man after the graft had been in place for 40 days. Fig. 7(A) shows the graft firmly in place and uniting to the host by organizing fibrosis (B). There was a severe inflammatory reaction, mainly in the host adventitia, which showed fibrosing arteriolitis (C), and heavy infiltration by cells which included numerous plasma cells (D).

Graft Detachment (Fig. 8). This occurred 10 days after insertion. The sutures tore away from the muscular septal part of the graft (A), its weakest point since it was comprised of friable, dead myocardium. The cusp was unaffected (B).

Cusp Perforation (Fig. 9). Fig. 9(A) shows perforation near the commissure of the right coronary cusp, which occurred $7 \frac{1}{2}$ months after insertion. There was no infection in the area, and the rupture was presumably due to hæmodynamic trauma 


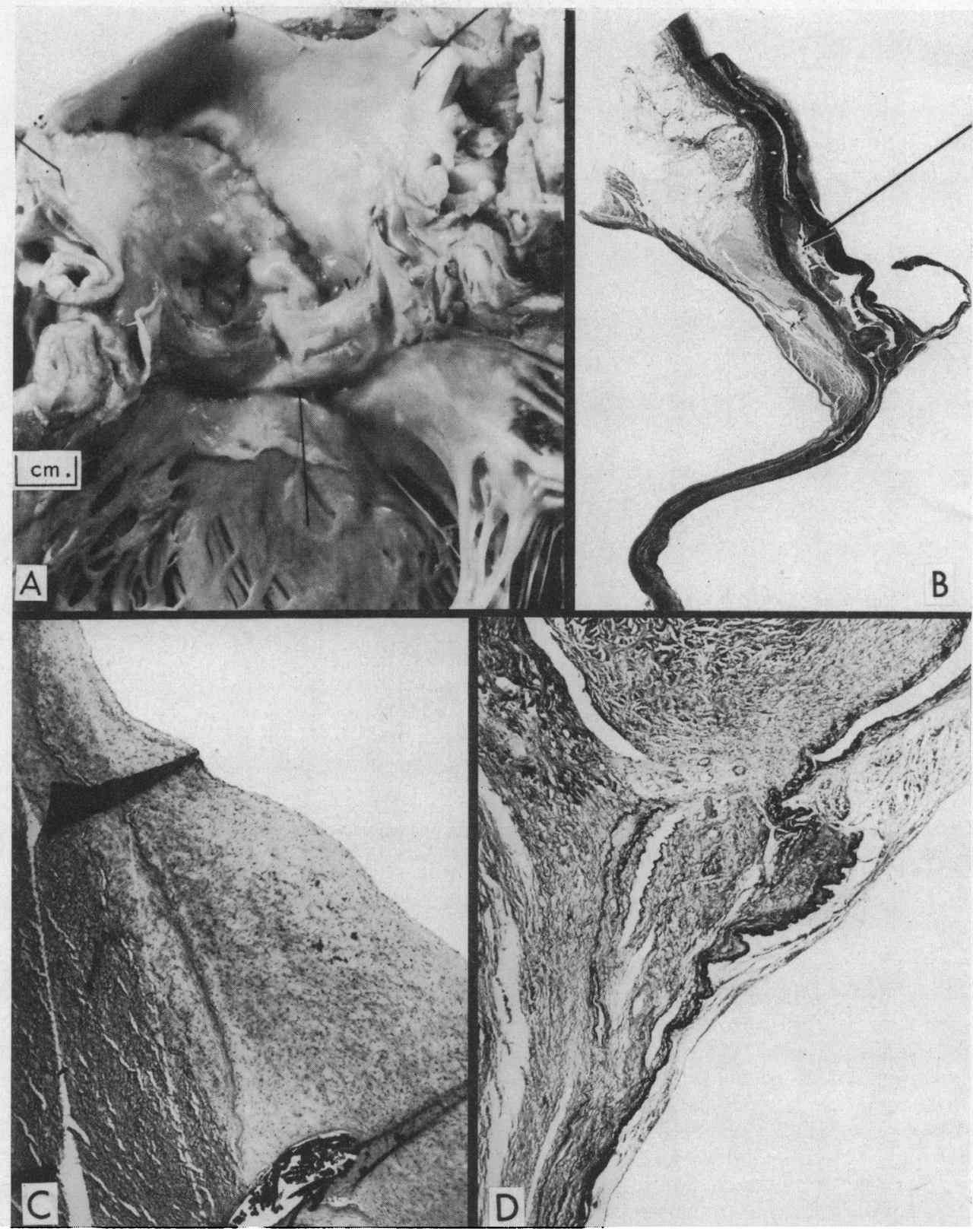

FIG. 5.-Homograft $5 \frac{1}{2}$ months after insertion in a woman of 47 years who had chronic rheumatic mitral and aortic stenosis and atrial fibrillation. At necropsy, there were numerous areas of cerebral softening, probably embolic; silicone antifoam was identified in the arterioles and capillaries of several organs besides the brain, but it was scanty. (A) The valve after cutting open. The sutures in the graft and aortic approach incision are almost completely buried in fibrous tissue-indeed, it is difficult to realize that the valve does not belong to the patient. The fibrosis on the bases of the cusps has spread on to the adjacent interventricular septum; the black bristle is inserted into a blind crevice between graft and host. Note the rheumatic mitral valve. (B) Longitudinal section through the graft and host tissues showing good union above and below; organizing thrombus lies in the space between (arrow). There is some thickening of the base of the valve cusp. (Elastic-van Gieson. $\times 2$.) (C) Upper, and (D), lower union of graft and host by fibrous tissue; note the gentle shelving of the surface. An anchoring suture is seen at the bottom of C. (C, hæmatoxylin and eosin; $\mathrm{D}$, elastic-van Gieson. Both $\times 32$.) 


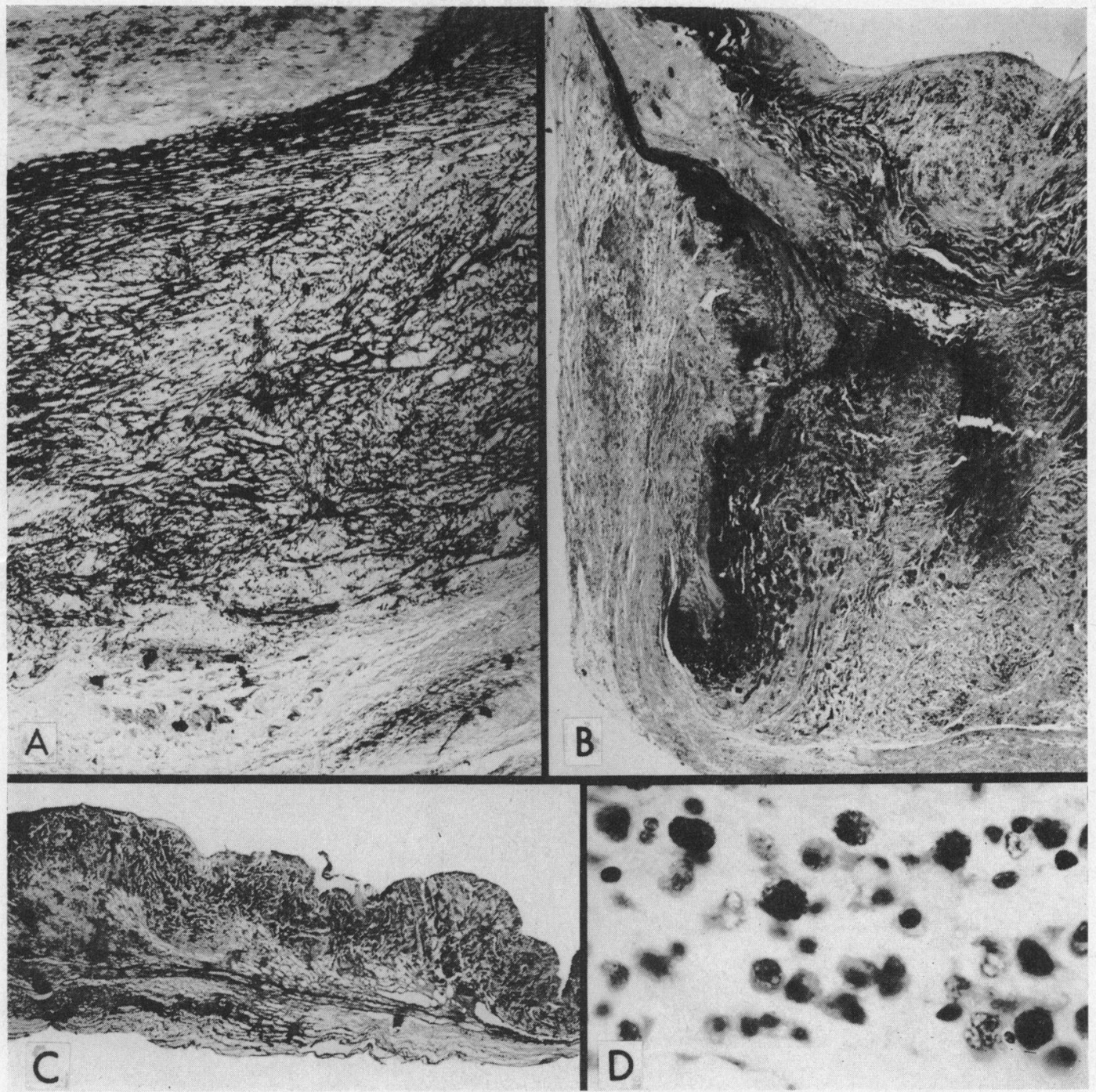

FIG. 6.-Graft histology 23 months after insertion in a man of 30 years who had bacterial endocarditis on a bicuspid aortic valve. The graft failed eventually, was removed, and replaced unsuccessfully by a caged-ball prosthesis. (A) Aortic media showing good preservation of elastic tissue. (B) Base of valve cusp showing the fibrosis on its surface (left) and in the sinus of Valsalva (top). The cusp itself extends out of the picture at the top left. (C) Valve cusps showing moderate thickening. (All elastic-van Gieson. $\times 34$.) (D) Focus of pyrinophilic cells, among which are plasma cells. (Pyronin. $\times 340$.) (Histology sections by courtesy of Dr. C. I. Roberts.)

through a weakened area of the cusp. After this period, the union of the graft and host was virtually complete, and the sutures were buried in the fibrous junction; the aortic sutures were similarly incorporated. At the same time, longitudinal section (B) shows considerable fibrous thickening of the base of the cusp.

Aortic Dissection. This occurred on 4 occasions; in 3 of these, it was known to be due to cannulation trauma of the atheromatous external iliac artery when establishing bypass. In one case, re-entry occurred into the distal aorta just proximal to the bifurcation, but in the other two, it raced proximally almost to the aortic valve ring in one and to the distal arch in the other. In both the severer cases, full dissection had occurred by the time the aorta was clamped and opened for valve replacement; one of these cases has already been reported in detail (see Dongaonkar, 1966). The fourth example was 


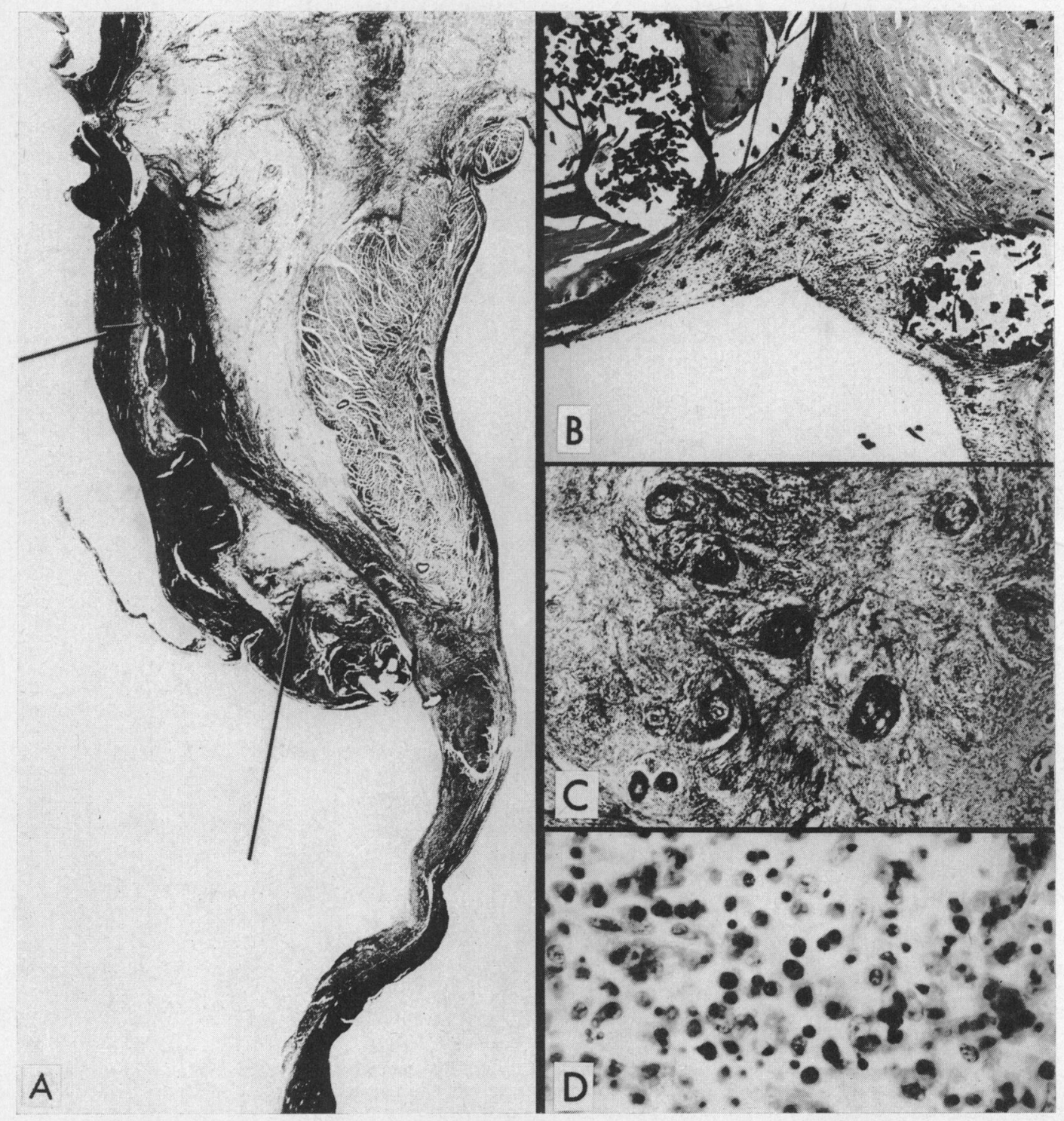

Fig. 7.-Inflammatory reaction which led to fatal hæmorrhage from the graft area in a man of 28 years whose graft had been inserted $\mathbf{4 0}$ days earlier. (A) Longitudinal section of graft and host tissues. There is good union by organizing fibrous tissue at both ends of the graft (the lower union is seen in B, together with sutures), but there is hæmorrhage and severe inflammatory reaction in the area between graft and host (arrows). There is also a similar adventitial inflammation in the host aorta, which shows fibrotic vasculitis $(C)$ and inflammatory cells, including numerous plasma cells (D). (A and C, elastic-van Gieson, A $\times 2.9$ and C $\times 34$; B and D, hæmatoxylin-eosin, $\mathrm{B} \times 34$ and $\mathrm{D} \times 340$.)

found only at necropsy and its origin was undecided; it was unusual in that three dissection spaces were excavated (see Hudson, 1965, Fig. 11.7).

Dissection of the aorta as a complication of calcific aortic valve stenosis is insufficiently recognized. The writer's attention was first drawn many years ago to the fragility of the hypoplastic aorta, in some cases by its tearing in two at diaphragm level during removal of the midline thoracic viscera from their posterior attachment at necropsy.

\section{Discussion}

This paper is a record of fatal cases only, and it would be proper to correct any impression this may 


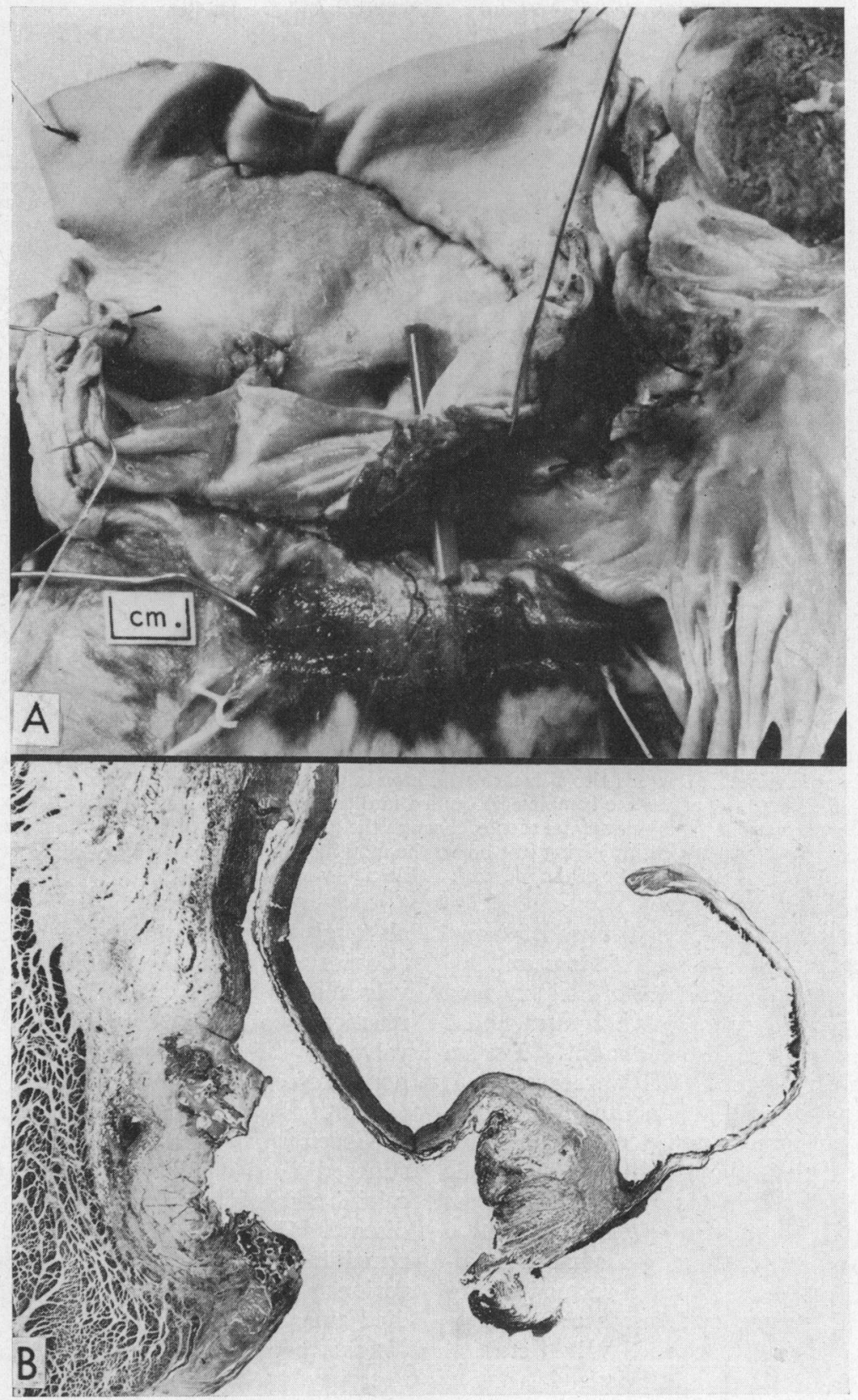

Fig. 8.-Graft detachment 10 days after insertion in a man of 43 years who had a bicuspid aortic valve; he died with post-operative jaundice and renal failure. He also developed heart block after operation, thought to be due to sutural injury. (A) Valve after cutting open; the lower border has become partially detached; the probe lies between graft and host. The area around the leak is thickened with fibrin stained deeply with bilirubin. (B) Longitudinal section to show the lower graft detachment. This emphasizes that the attachment of the graft, in the early weeks at least, depends entirely on its upper and lower rows of sutures. (Hæmatoxylin and eosin. $\times 4.4$.) 
give that aortic valve homografting is unsatisfactory, by citing the recent observations of Ross and his colleagues on 13 patients, 4 of whom had survived over 1 year, 5 over $1 \frac{1}{2}$ years, 2 over 2 years, and 1 over $2 \frac{1}{2}$ years after homograft replacement. Twelve (11 men, 1 woman, ages 29-60) were restudied, 7 undergoing cardiac catheterization and angiography; none had any increase of aortic valve stenosis or calcification, though all had a systolic murmur and 11 had a diastolic murmur; the heart size had reduced in the 3 with excellent and the 6 with good results. In 4 , there was some deterioration of valve function, 1 of which seemed due to possible ruptured suture and another to aortography. Immunological tests on 3 valves studied at re-operation or necropsy at 10 days, $2 \frac{1}{2}$, and 6 months showed no globulin deposits by direct antiglobulin staining. The host serum showed no antibodies to heart muscle by the tanned-cell technique or to valve tissue by an indirect fluorescence technique; the sera from 2 patients deposited globulin on the endomysial sheath of rat heart muscle fibres. None of these tests therefore disclosed a significant immune reaction and there was no need for steroid suppression therapy, although this was given in earlier cases of the series (Davies et al., 1965). Whether dead animal aortic valves of suitable size will evoke a more severe reaction in the human remains to be seen; such valves would certainly have the advantage over homograft valves of availability.

Barratt-Boyes (1964) reported a series of 44 cases at Green Lane Hospital in New Zealand; 21 had suffered from aortic valve regurgitation, 17 from calcific aortic valve stenosis, and 6 from multivalvar disease. There were only 3 hospital deaths; the remaining 41 had normally functioning valves for various periods up to 15 months after operation; 2 died unexpectedly, possibly from coronary artery disease, because the valves seemed satisfactory at necropsy.

A crucial factor in the success of valve replacement, assuming this to be technically correct, is the state of the left ventricular myocardium. The chamber is always dilated and often greatly hypertrophied; its function is already handicapped because this is what brings the patient to notice. The thickened muscle mass is inadequately nourished, and this is due to insufficient diastolic filling of the coronary arterial tree, which again is 
probably barely large enough for the size of the ventricle. Occasionally, the coronary arteries are actually stenosed by atheroma, but in most cases the writer has been impressed by the freedom of the main arterial segments from atheroma. This encouraging finding is the reason why the good functioning replacement valve can bring remarkable benefit in such cases. At surgery it is vital that the chronically undernourished myocardium of these patients be adequately perfused throughout operation to avoid the inevitable left ventricular failure which results if this is not done.

It might be expected that the suturing of the lower rim of the graft would endanger the bundle of His and its left fascicles, but heart block has not been an important feature of the 80 or more patients operated on by Ross, who is well aware of the hazard, as indeed are all experienced surgeons operating in this vital area. Two of the patients in the present account developed post-operative heart block, and one required artificial pacemaking.

The fibrous thickening of the bases of the cusps, which threatens to shorten the useful function of the graft, is probably the result of a combination of healing over the lower sutural union, together with fibrin deposition over the projecting tissue (as may happen at any such irregularities of the surface in the heart and great arteries) and in association with regurgitant eddies of blood, eventually becoming organized to fibrous tissue. The valve, provided it is a good fit, will continue to be satisfactory until this fibrous deposition interferes with the mobility of the cusps. This underlines the great skill and meticulous care which must be exercised by the surgeon to ensure as perfect a fit as possible.

\section{SUMMARY}

An account of the pathology of the successful aortic valve homograft at various stages, from the time of insertion up to 2 years later, is given, together with some of the complications in unsuccessful cases. These include the post-perfusion pulmonary syndrome, embolism, accidental ligation or cannulation-dissection of the coronary arteries, aortic hæmorrhage, graft detachment, cusp perforation, and bypass cannulation dissection of the iliac artery spreading throughout the aorta.

The graft is normally well accepted by the host and becomes firmly united along its upper and lower margins by fibrous tissue which covers the sutures and smooths out the junctions. There is almost no immune reaction to the dead foreign tissue and rejection problems do not arise.

The notable feature is the thickening of the bases of the cusps, and the writer considers that, as this extends, it will limit the useful life of these grafts, though they provide a valuable alternative to the man-made prosthesis.

I would like to thank Mr. Donald Ross for his keen but unbiased interest in my study; I am also grateful to my Staff who assisted me at necropsy, in histology, and in the preparation of this paper.

\section{REFERENCES}

Archer, G. G. (1965). Method of moulding autogenous tissue with a view to the manufacture of living cardiac valve prostheses. Brit. F. Surg., 52, 973.

Barratt-Boyes, B. G. (1964). Homograft aortic valve replacement in aortic incompetence and stenosis. Thorax, 19 , 131.

Beall, A. C., Morris, G. C., Cooley, D. A., and De Bakey, M. E. (1961). Homotransplantation of the aortic valve. F. thorac. cardiovasc. Surg., 42, 497.

Clarke, J. A. (1965). An x-ray microscopic study of the blood supply to the valves of the human heart. Brit. Heart F. 27, 420.

Davies, H., Lessof, M. H., Roberts, C. I., and Ross, D. N. (1965). Homograft replacement of the aortic valve. Follow-up studies in twelve patients. Lancet, 1, 926.

Dongaonkar, P. P. (1966). Acute aortic dissection following cannulation of the iliac artery. Brit. Heart f., 28, 431.

Duran, C. G., and Gunning, A. J. (1962). A method for placing a total homologous aortic valve in the subcoronary position. Lancet, 2,488 .

Hudson, R. E. B. (1965). Cardiovascular Pathology, Vol. 1, p. 514. Edward Arnold, London.

Kerwin, A. J., Lenkei, S. C., and Wilson, D. R. (1962). Aortic-valve homograft in the treatment of aortic insufficiency. Report of 9 cases, with 1 followed for 6 years. New Engl. F. Med., 266, 852.

Lam et al. (1952). Cited by d'Abreu, A. L. (1965). In Artificial cardiac valves. Med. News (Lond.), August 20th, p. 10.

Murray, G. (1956). Homologous aortic-valve-segment transplants as surgical treatment for aortic and mitral insufficiency. Angiology, 7, 466.

Nahas, R. A., Melrose, D. G., Sykes, M. K., and Robinson, B. (1965). Post-perfusion lung syndrome. Role of circulatory exclusion. Lancet, 2, 251.

Ross, D. N. (1962). Homograft replacement of the aortic valve. Lancet, $2,487$.

(1963). Surgical reconstruction of the aortic valve. Lancet, 1, 571 . 